\title{
Effect of the Molecular Weight on the Physicochemical Properties of Poly(lactic acid) Nanoparticles and on the Amount of Ovalbumin Adsorption
}

\author{
Juliana Palacio, * Víctor H. Orozco and Betty L. López \\ Ciencia de los Materiales, Universidad de Antioquia, Calle 62, No. 52-59, \\ Torre 1 Laboratorio 310, Medellín, Antioquia, Colombia
}

\begin{abstract}
Nanopartículas de poli(ácido lactico) (PLA) foram preparadas para serem usadas como plataformas potenciais em sistemas de vacinas. PLA comercial de elevado peso molecular $\left(\mathrm{PLA}_{\mathrm{Hмw}}\right)$ com $\mathrm{M}_{\mathrm{w}} 1,5 \times 10^{5}$ e PLA de baixo peso molecular $\left(\mathrm{PLA}_{\mathrm{LMW}}\right.$ ) $\operatorname{com} \mathrm{M}_{\mathrm{w}} 9,3 \times 10^{3}$ foram obtidos por policondensação direta a partir de D,L ácido lático e usados para preparar nanopartículas pelo método de deslocamento de solvente. $\mathrm{O}$ efeito do peso molecular nas propriedades físico-químicas dos polímeros, nas dispersões das nanopartículas e na quantidade de adsorção de ovalbumina (OVA) foi estudado. PLA $_{\mathrm{HMw}}$ e PLA $\mathrm{LMw}_{\mathrm{LM}}$ foram caracterizadas por espectroscopia de infravermelho com transformada de Fourier (FTIR), análise termogravimétrica (TGA), calorimetria diferencial de varredura de temperatura modulada (MTDSC) e cromatografia de permeação de gel (GPC). A distribuição do tamanho das partículas e potencial- $\zeta$ das dispersões obtidas foram medidas por espalhamento de luz dinâmico (DLS) e espectroscopia eletroacústica, respectivamente. A adsorção de ovalbumina em nanopartículas foi avaliada pelo método de Bradford. A dispersão de PLA $\mathrm{Lmw}_{\mathrm{L}}$ mostrou menores valores de potencial- $\zeta$ e tamanhos maiores comparados à dispersão de $\mathrm{PLA}_{\mathrm{HMw}}$. Uma menor adsorção de OVA foi alcançada por PLA ${ }_{\text {LMW. }}$.
\end{abstract}

Poly(lactic acid) (PLA) nanoparticles were prepared to be used as potential platform for vaccine systems. Commercial high molecular weight PLA ( $\mathrm{PLA}_{\text {Нмш }}$ ) with $\mathrm{M}_{\mathrm{w}} 1.5 \times 10^{5}$ and low molecular weight poly(lactic acid) $\left(\mathrm{PLA}_{\mathrm{LMW}}\right)$ with $\mathrm{M}_{\mathrm{w}} 9.3 \times 10^{3}$ were obtained by direct polycondensation from D,L lactic acid and used to prepare nanoparticles by solvent displacement method. The effect of the molecular weight on the physicochemical properties of the polymers, on the nanoparticles dispersions and the amount of ovalbumin (OVA) adsorption was studied. The PLA Hмw $_{\text {and PLA }}$ LMw were characterized by Fourier transformed infrared spectroscopy (FTIR), thermogravimetrical analysis (TGA), modulated temperature differential scanning calorimetry (MTDSC) and gel permeation chromatography (GPC). The particle size distribution and $\zeta$-potential of the obtained dispersions were measured by dynamic light scattering (DLS) and electroacoustic spectroscopy, respectively. The ovalbumin adsorption on nanoparticles was evaluated by the Bradford method. PLA $_{\text {LMw }}$ dispersion showed lower $\zeta$-potential values and larger sizes compared to PLA ${ }_{\mathrm{Hmw}}$ dispersion. A minor OVA adsorption was achieved for PLA $\mathrm{LMW}_{\text {. }}$

Keywords: poly(lactic acid), nanoparticles, ovalbumin, adsorption

\section{Introduction}

Polymeric nanoparticles have revealed to be a promising way to delivery and transport many kinds of therapeutic agents in vaccination, as well as in the introduction of broad and potent immune responses, long lasting antibodies, cytotoxic $\mathrm{T}$ lymphocythes and mucosal immunity. ${ }^{1-4}$ The nanoparticles may control and target the release and can be used to deliver or transport hydrophilic

*e-mail: juli.pb@gmail.com and hydrophobic drugs, nucleic acids, proteins, peptides and ions..$^{5-8}$ The advantages of using nanoparticles in these applications are the small size, surface characteristics, the controlled and sustained release during the transportation and the protection of the therapeutic agent against degradation (thus maintaining the bioactivity before the drug reaches the target). $5,9,10$

The surface nature of the nanoparticles can be easily tailored for improving intracellular uptake and targeting. The polymeric nanoparticle systems display more biological and dilution stability compared to liposome and 
micelle systems, which are very sensitive to concentration changes and chemical surroundings. Hence, polymeric nanoparticles are more suitable for scaling-up. ${ }^{9}$

According with the application needs, i.e. the desired delivery route and the physicochemical characteristics of the therapeutic agent, it is possible to choose the most suitable polymer and the preparation method. ${ }^{5,7}$ Due to the nanoparticle applications depicted above, they must be biocompatible and biodegradable..$^{5,9,11}$ Synthetic materials, ${ }^{12,13}$ proteins ${ }^{14,15}$ and other natural macromolecules ${ }^{16,17}$ have also been used.

Poly(lactic acid) (PLA) and its copolymers with poly(glycolic acid) (PLGA) and poly(ethylene glycol) (PLA-PEG) have received much attention for the preparation of nanoparticles for drug delivery or for controlled administration of different therapeutic agents. PLA is a linear aliphatic polymer derived from lactic acid. These structures consist of L-, D- and D,L-lactic acid, in which the D,L-polymer is amorphous and more rapidly degradable than their L- or D- isomers. This polymer is biocompatible and biodegradable, undergoing scission in the backbone during the degradation. The monomeric units of lactic acid are released as a natural intermediate in carbohydrate metabolism. This material has been approved by the U. S. Food and Drug Administration. ${ }^{7,11,12,18-21}$

Several methods have been used for the synthesis of PLA including direct polycondensation, azeotropic condensation and ring opening polymerization. ${ }^{11,22,23}$ PLA obtained by polymerization of lactic acid in presence of catalysts at reduced pressure presents low molecular weight. This happens since an equilibrium condensation is established due to the difficulty of removing water as by-product. ${ }^{24,25}$ Low molecular weight PLA is generally preferred than high molecular weight PLA in biomedical applications, where fast degradation into the human body is required. ${ }^{23,26}$ High molecular weight PLA polymers are usually obtained from ring opening polymerization of lactide and azeotropic condensation. Ring opening polymerization of lactide uses stannous, zinc or tin as catalyst and other heavy metal and protic acids, like $p$-toluenesulfonic and boric acid. These catalysts favor the reaction progress because of their ability to form metal-oxygen bonds and their free $p$ and $d$ orbitals. ${ }^{22}$ A protic acid favors the polycondensation, increases the kinetics and the yield of the reaction and prevents degradation. ${ }^{27-29}$

The azeotropic condensation is carried out without any chain extender or adjuvant. In this process, the lactic acid and catalyst are azeotropically dehydrated in a refluxing high-boiling point aprotic solvent under reduced pressure. This polymerization leads to a polymer with considerable catalyst impurities and may cause many problems such as unwanted degradation, non-reproducible hydrolysis rates and catalyst toxicity in medical applications..$^{22,23}$

There are several methods for preparing nanoparticles from preformed polymers as PLA such as emulsification/ solvent evaporation, solvent displacement, emulsion/solvent diffusion and salting out. ${ }^{9} 10,30-32$ The solvent displacement method has several advantages. Since the procedure is easy and straightforward to perform, the nanoparticle formation is instantaneous and the entire procedure is carried out in one step. The use of surfactants is optional and does not limit its application in medicine. Besides, this method reports high yields and allows scalling-up..$^{18,33-36}$

PLA nanoparticles are advantageous because they may provide controlled and sustained release. They are biocompatible, biodegradable, non-thrombogenic, non-immunogenic, non-inflammatory and non-toxic. They favor the uptake of reticule endothelial system without activating neutrophils. ${ }^{7}$ Controlled release can be readily modulated through particle degradation by choosing the constituents of the matrix..$^{31}$ The targeting can be achieved by attaching ligands to the particle surface. ${ }^{37}$ They have long term stability ${ }^{38}$ and can be administrated by oral, nasal, parenteral and intra-ocular ways. , $, 9,30,39^{2}$

Some parameters, such as polymer composition, hydrophobicity/hydrophilicity balance, surface charges, concentration and molecular weight of the polymer, influence the drug absorption, encapsulation, biodistribution, elimination ${ }^{10}$ and in vivo performance. ${ }^{5,7,11}$

The preformed polymer molecular weight is very important because influences the particles size and the drug or therapeutic agent encapsulation, adsorption or physicochemical interaction and release rate. ${ }^{717}$ Some authors have reported a direct relationship between polymer molecular weight and particle size for nanoparticles prepared from PLGA ${ }^{40-43}$ and chitosan. ${ }^{17,44}$ Different behavior has been reported for nanoparticles prepared from PLA where a low molecular weight polymer produces bigger nanoparticles compared to nanoparticles prepared from a higher molecular weight PLA. ${ }^{36,39,45}$

The ovalbumin (OVA) is a globular glycoprotein, which is readily available in large amounts. It has been well studied and completely characterized to be used as model antigen. The amino acid sequence of hen egg-white ovalbumin comprises 386 amino acids and the relative molecular weight is $45 \mathrm{kDa} .{ }^{46} \mathrm{In}$ addition, the synthesis of ovalbumin by hen oviduct and its regulation by steroid hormones have provided a model system in studies of protein synthesis and secretion.

This article studies the effect of poly(lactic acid) molecular weight on polymeric nanoparticle size, 
$\zeta$-potential and amount of ovalbumin adsorption. The nanoparticles were prepared from a commercial PLA of high molecular weight $\left(\mathrm{PLA}_{\mathrm{Hмw}}\right)$ and a low molecular weight PLA $\left(\mathrm{PLA}_{\mathrm{LMW}}\right)$ obtained by synthesis via polycondensation of $\mathrm{D}, \mathrm{L}$ lactic acid. The ovalbumin was used as model antigen.

\section{Experimental}

\section{Materials}

D,L lactic acid (98\%) and ovalbumin were obtained from Sigma-Aldrich, stannous octoate $\left(\mathrm{Sn}(\mathrm{Oct})_{2}\right)$ supplied from MP Biomedicals Inc. Ethanol, methanol and $p$-toluenesulfonic acid, were purchased from Merck. Phosphate buffered saline (PBS) was obtained from Gibco. The injection grade poly-(D,L-lactic acid) $\left(\mathrm{PLA}_{\text {нмш }}\right)$ was supplied by Jamplast Inc (Ellisville, USA). Acetone was received from J.T. Baker. Ultrapure water with a resistivity of $18.2 \mathrm{M} \Omega \mathrm{cm}$ was used (Nanopure system). The Bradford Assay Kit containing a Coomassie assay reagent was obtained from Fluka Chemika AG.

\section{Synthesis of low molecular weight PLA}

Low molecular weight poly(lactic acid) $\left(\mathrm{PLA}_{\mathrm{LMW}}\right)$ was synthesized by direct polycondensation of D,L lactic acid by using $p$-toluenesulfonic acid and stannous octoate as catalysts, as described by Orozco et al. ${ }^{23}$ Briefly, lactic acid was kept at continuous refluxing, under reduced pressure, with permanent magnetic stirring for $3 \mathrm{~h}$ at $60{ }^{\circ} \mathrm{C}$ in order to remove water, prevent degradation of the formed oligomers of poly(lactic acid) and of the sublimation of lactide, which may be produced during this step. Then, 0.5 wt. $\% \mathrm{Sn}(\mathrm{Oct})_{2}$ and $0.5 \mathrm{wt} . \%$ p-toluenesulfonic acid were added at the beginning of the polycondensation step. The system was heated up gradually to $160{ }^{\circ} \mathrm{C}$ and the temperature was kept constant for $10 \mathrm{~h}$. The polymeric product was purified by dissolving it in acetone and precipitated in water. Finally, the PLA was filtered and dried under reduced pressure.

\section{Polymer characterizations}

Fourier transformed infrared (FTIR) spectra of films of same thickness and amount of PLA $\mathrm{HMw}_{\text {and }}$ and $\mathrm{PLw}_{\mathrm{LM}}$ were recorded in a FTIR spectrometer Perkin Elmer Spectrum One model on a SeZn cell. Every spectrum was normalized for comparison purposes.

Thermogravimetric analysis (TGA) was carried out with a TA Instruments Q500. Each sample was run from
25 to $700^{\circ} \mathrm{C}$ at a heating rate of $10^{\circ} \mathrm{C} \mathrm{min}^{-1}$ under nitrogen atmosphere. Afterwards, the temperature was increased to $800^{\circ} \mathrm{C}$ using the same rate in air atmosphere.

Modulated temperature differential scanning calorimetry (MTDSC) was performed in a TA Instruments Q100 to determine glass transitions $\left(\mathrm{T}_{\mathrm{g}}\right)$, melting points $\left(\mathrm{T}_{\mathrm{m}}\right)$ and crystallization temperatures $\left(\mathrm{T}_{\mathrm{c}}\right)$. The thermal history was erased during the first run at a high heating rate up to $190^{\circ} \mathrm{C}$, followed by a fast cooling to $-50^{\circ} \mathrm{C}$. Then, the heating rate was modulated $\pm 1.0^{\circ} \mathrm{C} \mathrm{min}{ }^{-1}$ with a ramp $2.0^{\circ} \mathrm{C}$ min $^{-1}$ to $200{ }^{\circ} \mathrm{C}$. $\mathrm{T}_{\mathrm{g}}$ was evaluated base on ASTM D 3418 and calculated as the midpoint temperature.

The molecular weights were determined by gel permeation chromatography (GPC) on a Waters equipment with a quaternary pump controller model 600 and differential refractometer as a detector. Two columns type Waters Styragel HT 6E and HR 4E were used for the assessment of the molecular weights of PLA $\mathrm{HMw}_{\text {and }}$ and PLA $_{\text {LMW }}$, respectively. This system was operated at flow rates of 0.6 and $0.4 \mathrm{~mL} \mathrm{~min}^{-1}$, according with each column optimal operation conditions. The molecular weights were calculated by using calibration curves prepared from polystyrene standards in tetrahydrofurane at $31^{\circ} \mathrm{C}$ on the range of each column. . $^{23,47}$

\section{PLA nanoparticle preparations}

PLA nanoparticles were prepared by solvent displacement technique. ${ }^{18,19,34,47}$ Briefly, $50 \mathrm{mg}$ of PLA polymer were completely dissolved in $10 \mathrm{~mL}$ of acetone. ${ }^{35}$ The organic solution was introduced drop by drop in $20 \mathrm{~mL}$ of ultrapure water using a syringe under moderate magnetic stirring at room temperature, allowing the acetone to rapidly diffuse into the aqueous phase. The acetone was evaporated by continuous stirring during $24 \mathrm{~h}$ inside a laboratory hood, and the aqueous phase became opalescent due to formation of the nanoparticles. The prepared nanoparticles dispersions were storage at $4{ }^{\circ} \mathrm{C}$.

\section{Nanoparticle characterizations}

The particle size analysis of the aqueous dispersions was carried out in a Horiba LB 550 dynamic light scattering (DLS) equipment at room temperature.

The $\zeta$-potential of the PLA nanoparticle dispersions was measured using the electroacoustic colloidal vibration current (CVI) technique (DT 300 equipment, Dispersion Technology). The default frequency was $3 \mathrm{MHz}$. $\zeta$-potential measurements were performed in aqueous phase at $\mathrm{pH} 6.5$, as reported by Orozco et al. ${ }^{47}$ for polymeric nanoparticles. 


\section{Ovalbumin adsorption}

$500 \mu \mathrm{L}$ of 0.5 wt.\% PLA nanoparticles dispersion were mixed with $500 \mu \mathrm{L}$ OVA solution of $600.0 \mu \mathrm{g} \mathrm{mL}^{-1}$ in PBS $10 \mathrm{mmol} \mathrm{L}^{-1}(\mathrm{pH}$ 7.2). The adsorption procedure on the PLA nanoparticle surfaces was performed at room temperature and by continuous shaking in a Hiedolph vortex mixer at $250 \mathrm{rpm}$ for $24 \mathrm{~h}$. Then, the PLA-OVA nanoparticle dispersions were centrifuged for $20 \mathrm{~min}$ at $9000 \mathrm{rpm}$. The supernatants were drawn out and the amount of non-adsorbed OVA was quantified. Afterwards, the nanoparticles were resuspended in an ultrasound bath for $10 \mathrm{~min}$, then centrifuged, washed and resuspended as the former step. On this step, the amount of OVA which remained in solution was quantified again. ${ }^{4}$

\section{Ovalbumin quantification}

The amount of adsorbed OVA on the surface of nanoparticles was indirectly determined by measuring the amount of free protein in the supernatant after centrifugation via Bradford method (595 nm). The difference between the initial amount of OVA and the final amount in the supernatant allowed to calculate the amount of adsorbed OVA on PLA nanoparticles.

\section{Results and Discussion}

In order to remove residual monomer, catalysts and impurities, which may affect further processes, the synthesized polymer $\left(\mathrm{PLA}_{\mathrm{LMW}}\right)$ and the pellets of commercial PLA $_{\mathrm{HMw}}$ were purified, as it was depicted above. After purification, PLA $_{\text {LMw }}$ looks as a white fine powder and PLA $\mathrm{PMW}_{\mathrm{HM}}$ as white fibrous material.

\section{Gel permeation chromatography characterization}

Since the molecular weight has great influence in the colloidal stability, size, morphology, degradation time, surface functionalities and interaction with active agents, it was measured by gel permeation chromatography (GPC). Table 1 shows the number average molecular weight $\left(M_{n}\right)$, weight average molecular weight $\left(M_{w}\right)$ of

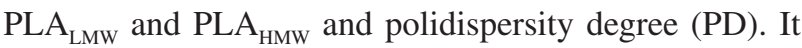

Table 1. Molecular weight of high molecular weight poly(lactic acid) $\left(\mathrm{PLA}_{\mathrm{LMW}}\right)$ and low molecular weight poly(lactic acid) $\left(\mathrm{PLA}_{\mathrm{LMW}}\right)$

\begin{tabular}{lccc}
\hline PLA & $\mathrm{M}_{\mathrm{w}} /\left(\mathrm{g} \mathrm{mol}^{-1}\right)$ & $\mathrm{M}_{\mathrm{n}} /\left(\mathrm{g} \mathrm{mol}^{-1}\right)$ & $\mathrm{PD}$ \\
\hline PLA $_{\mathrm{LMW}}$ & $9.3 \times 10^{3}$ & $7.6 \times 10^{3}$ & 1.2 \\
$\mathrm{PLA}_{\mathrm{HMW}}$ & $1.5 \times 10^{5}$ & $7.7 \times 10^{4}$ & 1.9 \\
\hline
\end{tabular}

is clear the large difference in molecular weight between the samples, allowing further analysis based on molecular weight differences.

\section{Fourier transformed infrared spectroscopy characterization}

Although both structures PLA $_{\mathrm{LMw}}$ and $\mathrm{PLA}_{\mathrm{HMw}}$ are very similar, there are some differences on the FTIR spectra (Figure 1), which correspond to the differences on molecular weight of the samples, as shown in Figure 1c. The main differences on the spectra must be related to the amount of end functional groups and the ester bonds, because PLA ${ }_{\text {LMW }}$ has more carboxylic acid and alcohol groups per mass of sample compared to PLA $_{\text {Hмw. }}$.
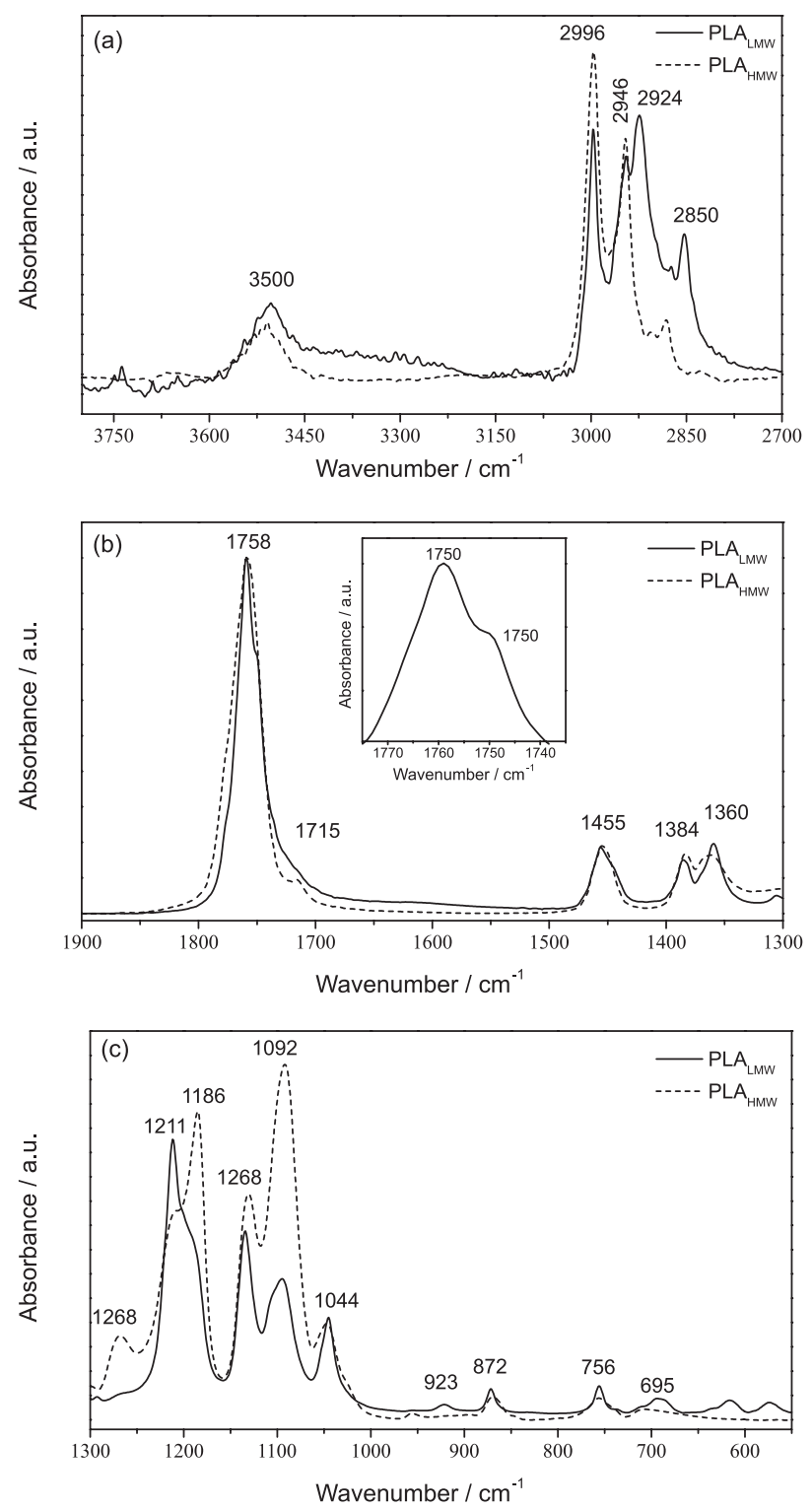

Figure 1. FTIR spectra of $\mathrm{PLA}_{\mathrm{HMW}}$ (dash line) and $\mathrm{PLA}_{\mathrm{LMW}}$ (solid line): (a) 3800 to $2700 \mathrm{~cm}^{-1}$, (b) 1900 to $1300 \mathrm{~cm}^{-1}$ and (c) 1300 to $550 \mathrm{~cm}^{-1}$. 
Conversely, PLA $\mathrm{HMw}_{\mathrm{HM}}$ has higher amounts of ester bonds compared to $\mathrm{PLA}_{\mathrm{LMW}}$, since the enlarging the polymeric chain is given by reactions of carboxylic acids and alcohol functionalities, producing ester bonds.

According with these assignments, for $\mathrm{PLA}_{\mathrm{LMW}},-\mathrm{OH}$ stretch band coming from alcohol and carboxylic acid located at $c a .3500 \mathrm{~cm}^{-1}$ is more intense. The sharp band at $2996 \mathrm{~cm}^{-1}$ corresponding to the $-\mathrm{C}-\mathrm{H}$ asymmetric stretch is less intense compared to the corresponding bands of $\mathrm{PLA}_{\mathrm{HMW}}$, as can be confirmed on the spectra in Figure 1a. ${ }^{22,48,49}$

The vibrational frequencies for the stretching of the carbonyl group also showed some differences. They appear at $1750 \mathrm{~cm}^{-1}$ for carboxylic acid and at $1758 \mathrm{~cm}^{-1}$ for ester group for $\mathrm{PLA}_{\mathrm{LMW}}$ (see the inset) and two resolved signals at 1715 and $1758 \mathrm{~cm}^{-1}$, respectively for PLA $\mathrm{HMW}_{\mathrm{H}}$, as shown in Figure $1 b$.

The asymmetric and symmetric bendings for $-\mathrm{CH}_{3}$ group are found at 1455 and $1383 \mathrm{~cm}^{-1}$, respectively. The vibration of $-\mathrm{CH}$ group at $1360 \mathrm{~cm}^{-1}$ is sharper for

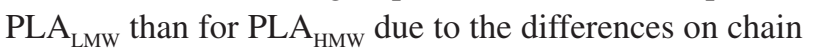
conformational arranges in each polymer.

Figure $1 \mathrm{c}$ shows the $1300-550 \mathrm{~cm}^{-1}$ range. The bend of carbonyl ester group appears at $1268 \mathrm{~cm}^{-1}$. This is stronger for PLA $_{\text {HMW }}$ compared to PLA $\mathrm{LMW}_{\mathrm{LMW}}$ due to the difference on the amount of ester links. The band at $1211 \mathrm{~cm}^{-1}$ corresponds to $-\mathrm{OC}-\mathrm{O}$ stretching of carboxylic group. This band is more intense for $\mathrm{PLA}_{\mathrm{LMw}}$ than for $\mathrm{PLA}_{\mathrm{HMw}}$ because of the higher relative amount of carboxylic groups with respect to ester bonds in the same amount of sample. The bands at 1183, 1130 and $1092 \mathrm{~cm}^{-1}$ correspond to the-OCC-related to ester functionalities. They present an opposite behavior due to the differences already depicted on the amount of functional groups.

\section{Thermogravimetric analysis and modulated temperature differential calorimetry characterization}

Table 2 presents thermal decomposition temperatures and thermal transitions of PLA samples. Both polymers presented only one weight loss. The PLA $\mathrm{L}_{\mathrm{LMW}}$ starts to decompose at lower temperature than $\mathrm{PLA}_{\mathrm{HMw}}$. This behavior is explained by the large difference on the molecular weight. ${ }^{50}$

The thermal behavior of $\mathrm{PLA}_{\mathrm{LMW}}$ and $\mathrm{PLA}_{\mathrm{HMW}}$ is similar and shows the same thermal events. A typical PLA MTDSC thermogram is presented in Figure 2 and the thermal transitions are summarized in Table 2. On the reversible cycle, glass transition $\left(\mathrm{T}_{\mathrm{g}}\right)$ and a broad endothermic peak corresponding to the melting point $\left(\mathrm{T}_{\mathrm{m}}\right)$ are observed. The temperatures are lower for $\mathrm{PLA}_{\mathrm{LMW}}$ than for $\mathrm{PLA}_{\mathrm{HMW}}$, as expected. A sharp
Table 2. Thermal stability and thermal transition of PLA samples

\begin{tabular}{lcccc}
\hline \multirow{2}{*}{$\begin{array}{l}\text { Type of } \\
\text { polymer }\end{array}$} & \multirow{2}{*}{$\begin{array}{c}\text { Decomposition } \\
\text { temperature } /{ }^{\circ} \mathrm{C}\end{array}$} & \multicolumn{3}{c}{ Thermal transitions $/{ }^{\circ} \mathrm{C}$} \\
\cline { 3 - 5 } & 281 & $\mathrm{~T}_{\mathrm{g}}$ & $\mathrm{T}_{\mathrm{c}}$ & $\mathrm{T}_{\mathrm{m}}$ \\
\hline $\mathrm{PLA}_{\mathrm{LMW}}$ & 382 & 45 & 84 & 127 \\
$\mathrm{PLA}_{\text {HMW }}$ & & 60 & 110 & 147 \\
\hline
\end{tabular}

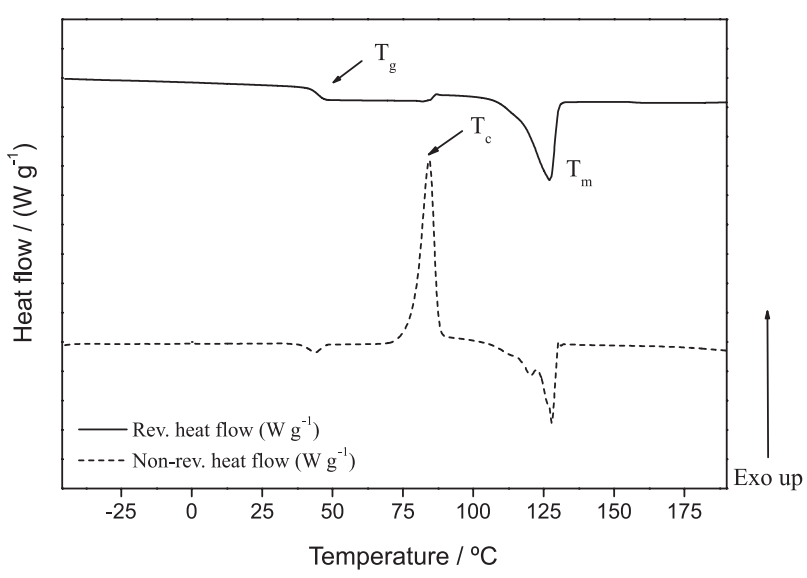

Figure 2. Typical modulated temperature differential scanning calorimetry of PLA (PLA LMW $_{\text {). }}$

exothermic peak of the crystallization temperature $\left(T_{c}\right)$ appears on the non-reversible cycle. The lower value of $T_{c}$ for PLA $A_{L M W}$ is due to the facility that the shorter chains have to orient and fit into a crystalline matrix. $33,42,43,51$

\section{Nanoparticle preparations}

The used process for nanoparticle preparation is based on the Marangoni effect, an interfacial turbulence phenomenon triggered by surface tension gradients, which are induced by gradients in temperature, concentration and surface charge through the interface. ${ }^{52,53}$ Hence, the rate of the mass transfer across the interface determines how fast the water miscible solvent diffuses to the non-solvent and controls the nanoparticle size. Therefore, it would be expected that a less viscous polymer solution would produce smaller nanoparticles compared to a more viscous polymer solution.

The viscosity of a polymer solution is a function of the concentration and the molecular weight of the polymer. Therefore, it is expected that higher molecular weight polymer solutions lead to larger nanoparticle sizes at a constant concentration of the same polymer. ${ }^{33,54}$ This behavior has been reported for chitosan ${ }^{17,44}$ and PLGA. ${ }^{40,41,43}$

\section{Nanoparticle characterization}

All the size distributions were calculated as intensity of scattered light and monomodal size distributions were 
obtained. Figure $3 \mathrm{a}$ shows the size distribution of the initial systems of OVA, PLA $\mathrm{HMW}_{\mathrm{HM}}$ and PLA $_{\mathrm{LMW}}$ before and after $\mathrm{pH}$ adjustment and Table 3 summarizes the size

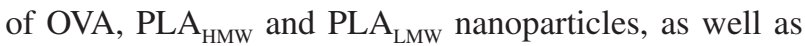
the $\zeta$-potential. As can be seen, the size of polymeric nanoparticles increases along with the decreasing of molecular weight. That is according with the literature reports for PLA, ${ }^{36,39,45}$ but contrary to the reported behavior for chitosan and PLGA, as mentioned above.
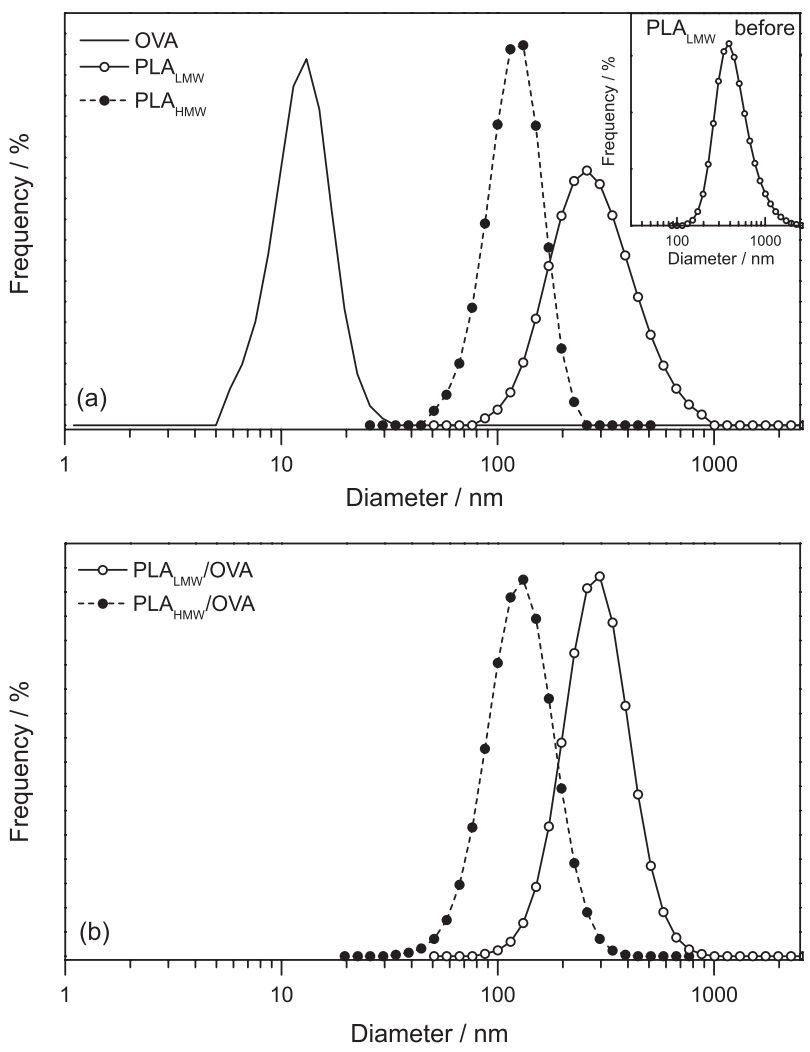

Figure 3. Size distribution of the PLA nanoparticle dispersions of (a) OVA (solid line), PLA $_{\text {HMW }}$ (solid circle on dash line) and PLA LMW $_{\text {(open }}$ circle on solid line) after $\mathrm{pH}$ adjustment, inset $\mathrm{PLA}_{\mathrm{LMW}}$ (open circle on solid line) before $\mathrm{pH}$ adjustment and (b) $\mathrm{PLA}_{\mathrm{HMw}} / \mathrm{OVA}$ and $\mathrm{PLA}_{\mathrm{LMW}} / \mathrm{OVA}$.

Table 3. Average size and $\zeta$-potential of the nanoparticles and dispersions before and after OVA adsorption

\begin{tabular}{lccc}
\hline Sample & $\begin{array}{c}\text { Size / nm } \\
(\mathrm{pH} 6.5)\end{array}$ & $\begin{array}{c}\zeta \text {-potential / } \\
\mathrm{mV}\end{array}$ & $\begin{array}{c}\text { Size / nm } \\
\text { (adsorbed) }\end{array}$ \\
\hline OVA & $12.0 \pm 4.0$ & $-12.0 \pm 0.3$ & - \\
PLA $_{\text {LMW }}$ & $235.0 \pm 58.0$ & $-51.0 \pm 0.3$ & $281.0 \pm 95.0$ \\
PLA $_{\text {HMW }}$ & $111.0 \pm 32.0$ & $-41.0 \pm 0.3$ & $118.0 \pm 40.0$ \\
\hline
\end{tabular}

The influence of the $\mathrm{pH}$ dispersion was studied since this parameter affects the size, $\zeta$-potential and colloidal stability. As expected, the $\mathrm{pH}$ of the nanoparticle dispersions prepared from PLA $\mathrm{LMW}_{\mathrm{L}}$ was lower than the dispersion prepared from PLA $_{\text {нмш }}$, as shown in the inset in Figure 3a. The $\mathrm{pH}$ of the $\mathrm{PLA}_{\mathrm{LMW}}$ after the nanoparticle preparation was 3.9 and the mean size of the particles was higher than $450.0 \mathrm{~nm}$. The $\mathrm{pH}$ for the dispersion of the $\mathrm{PLA}_{\text {нмш }}$ after the nanoparticle preparation was 6.5 and the size was $111.0 \mathrm{~nm}$. In order to study the $\mathrm{pH}$ effect, the PLA $_{\mathrm{LMW}}$ dispersion was adjusted to 6.5 and the nanoparticle size was reduced to $235.0 \mathrm{~nm}$, as can be seen in Table 3 and compared in the inset in Figure 3a.

The unexpected increase on the nanoparticle sizes with the decrease of molecular weight can be explained as follows. Since the PLA nanoparticle stabilization is more electrostatic than steric, and this electrostatic stabilization is given by the repulsion of the negative charges of deprotonated carboxylic acid groups, the $\mathrm{pH}$ of the dispersion is a very important parameter that governs colloidal stability. Thus, low $\mathrm{pH}$ favors aggregation processes, increasing the size of nanoparticles. This happens because of diminishing of the deprotonated end groups and of the increase of the probability of hydrogen bond formation among hydroxyl groups coming from acid groups and carbonyl groups of the ester group on polymer backbone.

Similarly, the molecular weight affects the $\zeta$-potential of the prepared dispersions. This $\zeta$-potential decreases along with the increase of the molecular weight due to the differences in the physicochemical characteristics of each polymer. Shorter chains mean more carboxylic acid end groups per mass, therefore more carboxylate groups or negative charges. Hence, dispersions prepared from $\mathrm{PLA}_{\mathrm{LMW}}$ are more acid than those prepared from larger polymers. This behavior has been reported before by Orozco et al. ${ }^{47}$ Both polymers produce colloidal dispersions with excellent stability before and after OVA adsorption.

\section{Ovalbumin adsorption}

Adsorption is a surface process wherein the main interactions between nanoparticles and protein should be electrostatic and hydrophilic/hydrophobic. ${ }^{45,55}$ Figure $3 \mathrm{~b}$ presents the particle size distributions of the dispersions after the OVA adsorption, small increments in particle size can be observed. This is probably associated to the OVA adsorption. Table 4 shows the amount of adsorbed OVA for each sample, as well as the calculated specific surface area for each sample. The specific surface area was calculated from the mean sizes of the dispersions and assuming spherical shape of the nanoparticles.

The OVA adsorption for PLA $_{\text {нмш }}$ nanoparticles is higher than the nanoparticles prepared from PLA $\mathrm{LMW}_{\mathrm{LW}}$. As depicted above, nanoparticles prepared from a high molecular weight commercial polymer are more hydrophobic due to longer aliphatic chains. In addition, the less negative $\zeta$-potential 
Table 4. Adsorbed ovalbumin and calculated specific surface area of nanoparticles prepared from PLA $\mathrm{HMw}_{\text {and }}$ PLA $\mathrm{LMW}_{\mathrm{H}}$

\begin{tabular}{lcc}
\hline Sample & $\begin{array}{c}\text { OVA adsorption / } \\
\left(\mu \mathrm{g}_{\text {OVA }} \mathrm{mg}_{\mathrm{PLA}^{-1}}{ }^{-1}\right.\end{array}$ & $\begin{array}{c}\text { Specific surface area / } \\
\left(\mathrm{m}^{2} \mathrm{~g}^{-1}\right)^{\mathrm{a}}\end{array}$ \\
\hline PLA $_{\mathrm{LMW}}$ & 18 & 21 \\
PLA $_{\mathrm{HMW}}$ & 47 & 42 \\
\hline
\end{tabular}

${ }^{a}$ Specific surface area calculated from the average size of the nanoparticles.

of these nanoparticle dispersions favors the interaction with OVA because of the decrease of the electrostatic repulsion with a protein that also has negative $\zeta$-potential. Hence, it is highly probable that the main interaction which governs the adsorption is the hydrophobic nature of the surface of the PLA ${ }_{\text {нмш }}$ nanoparticles. This hydrophobic nature allows the interaction with the high amount of hydrophobic amino acids coming from the OVA ( $41 \%$ of the total amino acids). ${ }^{46,56}$ The significant difference in the specific surface area is an additional parameter that adds a favorable effect to the hydrophobic character, because PLA $_{\text {нмш }}$ presents high specific surface area.

\section{Conclusions}

This work showed the possibility of obtaining poly(lactic acid) of low molecular weight by direct polycondensation. The poly(lactic acid) of low molecular weight showed to be sufficiently hydrophobic to form stable nanoparticles at $\mathrm{pH} 6.5$ since the solvent displacement method requires non-water soluble preformed polymer. In addition, it was found that the formation and the colloidal stability of PLA nanoparticles are strongly dependent on $\mathrm{pH}$ of the aqueous dispersion. The molecular weight is a highly important parameter and modifies the physicochemical properties of the polymer and of the nanoparticle dispersion. Moreover, the molecular weight strongly influences the capacity of OVA adsorption on the nanoparticle surface due to the differences on the magnitude of the electrostatic and hydrophobic interactions. These interactions are governed for the length of polymer chains. Low molecular weights lead to increase of the nanoparticle size, to diminish of the $\zeta$-potential and the OVA adsorption.

The displacement method is easy, provides good yield and good reproducibility, besides the adsorption methodology is simple and presents enough amount of protein antigen to be used in vaccine systems.

\section{Acknowledgments}

The authors wish to thank Colciencias for the financial support to the project code 1115-452-21346, corresponding to the No. $439-2008$.

\section{References}

1. Bajpai, A. K.; Shukla, S. K.; Bhanu, S.; Kankane, S.; Prog. Polym. Sci. 2008, 33, 1088.

2. des Rieux, A.; Fievez, V.; Garinot, M.; Schneider, Y.-J.; Préat, V.; J. Controlled Release 2006, 116, 1.

3. Jain, A. K.; Goyal, A. K.; Gupta, P. N.; Khatri, K.; Mishra, N.; Mehta, A.; Mangal, S.; Vyas, S. P.; J. Controlled Release 2009, 136, 161.

4. Lamalle-Bernard, D.; Munier, S.; Compagnon, C.; Charles, M.-H.; Kalyanaraman, V. S.; Delair, T.; Verrier, B.; Ataman-Önal, Y.; J. Controlled Release 2006, 115, 57.

5. Hans, M. L.; Lowman, A. M.; Curr. Opin. Solid State Mater. Sci. 2002, 6, 319.

6. He, C.; Hu, Y.; Yin, L.; Tang, C.; Yin, C.; Biomaterials 2010 , $31,3657$.

7. Kumari, A.; Yadav, S. K.; Yadav, S. C.; Colloids Surf., B 2010 , $75,1$.

8. Xu, F.; Yuan, Y.; Shan, X.; Liu, C.; Tao, X.; Sheng, Y.; Zhou, H.; Int. J. Pharm. 2009, 377, 199.

9. Galindo-Rodriguez, S.; Allémann, E.; Fessi, H.; Doelker, E.; Pharm. Res. 2004, 21, 1428.

10. Pinto Reis, C.; Neufeld, R. J.; Ribeiro, A. J.; Veiga, F.; Nanomed. Nanotechnol. Biol. Med. 2006, $2,8$.

11. Gupta, A. P.; Kumar, V.; Eur. Polym. J. 2007, 43, 4053.

12. Ataman-Önal, Y.; Munier, S.; Ganée, A.; Terrat, C.; Durand, P.-Y.; Battail, N.; Martinon, F.; Le Grand, R.; Charles, M.-H.; Delair, T.; Verrier, B.; J. Controlled Release 2006, $112,175$.

13. Harush-Frenkel, O.; Bivas-Benita, M.; Nassar, T.; Springer, C.; Sherman, Y.; Avital, A.; Altschuler, Y.; Borlak, J.; Benita, S.; Toxicol. Appl. Pharmacol. 2010, 246, 83.

14. Anal, A. K.; Tobiassen, A.; Flanagan, J.; Singh, H.; Colloids Surf., B 2008, 64, 104.

15. Langer, K.; Coester, C.; Weber, C.; von Briesen, H.; Kreuter, J.; Eur. J. Pharm. Biopharm. 2000, 49, 303.

16. Agnihotri, S. A.; Mallikarjuna, N. N.; Aminabhavi, T. M.; J. Controlled Release 2004, 100, 5.

17. Yang, H.-C.; Hon, M.-H.; Microchem. J. 2009, 92, 87.

18. Plapied, L.; Duhem, N.; des Rieux, A.; Préat, V.; Curr. Opin. Colloid Interface Sci. 2011.

19. Ribeiro, H. S.; Chu, B.-S.; Ichikawa, S.; Nakajima, M.; Food Hydrocolloids 2008, 22, 12.

20. Soppimath, K. S.; Aminabhavi, T. M.; Kulkarni, A. R.; Rudzinski, W. E.; J. Controlled Release 2001, 70, 1.

21. Xiong, L.; He, Z.; Polym.-Plast. Technol. Eng. 2010, 49, 1201.

22. Garlotta, D.; J. Polym. Environ. 2001, 9, 63.

23. Orozco, V. H.; Vargas, A. F.; López, B. L.; Macromol. Symp. 2007, 258, 45.

24. Harshe, Y. M.; Storti, G.; Morbidelli, M.; Gelosa, S.; Moscatelli, D.; Macromol. React. Eng. 2007, 1, 611. 
25. Kim, K. W.; Woo, S. I.; Macromol. Chem. Phys. 2002, 203, 2245.

26. Chen, G.-X.; Kim, H.-S.; Kim, E.-S.; Yoon, J.-S.; Eur. Polym. J. 2006, $42,468$.

27. Hyon, S.-H.; Jamshidi, K.; Ikada, Y.; Biomaterials 1997, 18, 1503.

28. Kohn, F. E.; van den Berg, J. W. A.; van de Ridder, G.; Feijen, J.; J. Appl. Polym. Sci. 1984, 29, 4265.

29. Moon, S. I.; Lee, C. W.; Miyamoto, M.; Kimura, Y.; J. Polym. Sci., Part A: Polym. Chem. 2000, 38, 1673.

30. Mohanraj, V.; Chen, Y.; Tropical J. Pharm. Res. 2006, 5, 561.

31. Ogier, J.; Arnauld, T.; Doris, E.; Future Med. Chem. 2009, 1, 693.

32. Quintanar-Guerrero, D.; Allemann, E.; Fessi, H.; Doelker, E.; Drug Dev. Ind. Pharm. 1998, 24, 1113.

33. Bilati, U.; Allémann, E.; Doelker, E.; Eur. J. Pharm. Sci. 2005, 24, 67.

34. Fessi, H.; Puisieux, F.; Devissaguet, J. P.; Ammoury, N.; Benita, S.; Int. J. Pharm. 1989, 55, R1.

35. Legrand, P.; Lesieur, S.; Bochot, A.; Gref, R.; Raatjes, W.; Barratt, G.; Vauthier, C.; Int. J. Pharm. 2007, 344, 33.

36. Zambaux, M. F.; Bonneaux, F.; Gref, R.; Maincent, P.; Dellacherie, E.; Alonso, M. J.; Labrude, P.; Vigneron, C.; J. Controlled Release 1998, 50, 31.

37. Narayanan, S.; Binulal, N. S.; Mony, U.; Manzoor, K.; Nair, S.; Menon, D.; Nanotechnology 2010, 21, 1.

38. Espuelas, S.; Gaz. Méd. Bahia 2009, 79, 134.

39. Belbella, A.; Vauthier, C.; Fessi, H.; Devissaguet, J.-P.; Puisieux, F.; Int. J. Pharm. 1996, 129, 95.

40. Blanco, M. D.; Alonso, M. J.; Eur. J. Pharm. Biopharm. 1997, 43, 287.

41. Mehta, R. C.; Thanoo, B. C.; Deluca, P. P.; J. Controlled Release 1996, 41, 249.
42. Prieto, M. J. B.; Delie, F.; Fattal, E.; Tartar, A.; Puisieux, F.; Gulik, A.; Couvreur, P.; Int. J. Pharm. 1994, 111, 137.

43. Sameni, J.; Bukhari, N. I.; Azlan, N. A.; Julianto, T. ; Majeed, A. B. A.; Industrial Electronics \& Applications, ISIEA 2009, IEEE Symposiumon 2009, 2009, p. 700 (document available under request to authors).

44. Park, K.; Kwon, I. C.; React. Funct. Polym. 2011, 71, 280.

45. Zambaux, M. F.; Bonneaux, F.; Gref, R.; Dellacherie, E.; Vigneron, C.; J. Controlled Release 1999, 60, 179.

46. Huntington, J. A.; Stein, P. E.; J. Chromatogr. B 2001, 756, 189.

47. Orozco, V. H.; Kozlovskaya, V.; Kharlampieva, E.; López, B. L.; Tsukruk, V. V.; Polymer 2010, 51, 4127.

48. Coates, J. In Encyclopedia of Analytical Chemistry; John Wiley \& Sons, Ltd: Newtown, 2006.

49. Achmad, F.; Yamane, K.; Quan, S.; Kokugan, T.; Chem. Eng. J. 2009, 151, 342.

50. Shaver, M. P.; Cameron, D. J. A.; Biomacromolecules 2010 , 11,3673 .

51. Di Lorenzo, M. L.; Eur. Polym. J. 2005, 41, 569.

52. D’Aubeterre, A.; Silva, R.; Aguilera, M. E.; Int. Commun. Heat Mass Transfer. 2005, 32, 677.

53. Sternling, C. V.; Scriven, L. E.; AIChE Journal 1959, 5, 514.

54. Mosqueira, V. C. F.; Legrand, P.; Pinto-Alphandary, H.; Puisieux, F.; Barratt, G.; J. Pharm. Sci. 2000, 89, 614.

55. Nisbet, A. D.; Saundry, R. H.; Moir, A. J. G.; Fothergill, L. A.; Fothergill, J. E.; Eur. J. Biochem. 1981, 115, 335.

56. Thompson, E. O.; Fisher, W. K.; Aust. J. Biol. Sci. 1978, 31, 433.

Submitted: March 30, 2011 Published online: September 13, 2011 